\title{
Mesocorticolimbic Connectivity and Volumetric Alterations in DCC Mutation Carriers
}

\author{
Daniel E. Vosberg, ${ }^{1,3 *}$ () Yu Zhang, ${ }^{2 *}$ () Aurore Menegaux, ${ }^{4,7,8}$ Amanda Chalupa, ${ }^{1}$ Colleen Manitt, ${ }^{4}$ Simone Zehntner, ${ }^{6}$ \\ Conrad Eng, ${ }^{4}$ @ Kristina DeDuck, ${ }^{2}$ Dominique Allard, ${ }^{1}$ France Durand, ${ }^{1}{ }^{\circledR}$ Alain Dagher,,${ }^{2,3}$ Chawki Benkelfat, ${ }^{1,2,3}$ \\ Myriam Srour, ${ }^{2}$ QRidha Joober, ${ }^{1,3,4}$ Franco Lepore, ${ }^{5}$ Guy Rouleau, ${ }^{2}$ Hugo Théoret, ${ }^{5}$ Barry J. Bedell, ${ }^{2}$ CCecilia Flores, ${ }^{1,2,3,4}$ \\ and $\oplus^{-M a r c o}$ Leyton ${ }^{1,2,3}$ \\ ${ }^{1}$ Department of Psychiatry, ${ }^{2}$ Department of Neurology and Neurosurgery, ${ }^{3}$ Integrated Program in Neuroscience, McGill University, Montreal, Quebec H3A \\ 0G4, Canada, ${ }^{4}$ Douglas Mental Health University Institute, Montreal, Quebec H4H 1R3, Canada, ${ }^{5}$ Département de psychologie, Université de Montréal, \\ Montreal, Quebec H2V 2S9, Canada, ${ }^{6}$ Biospective, Montreal, Quebec H3B 2T9, Canada, ${ }^{7}$ Department of Psychology, General and Experimental Psychology, \\ and ${ }^{8}$ Graduate School of Systemic Neurosciences, Ludwig-Maximilians-Universität München, 80802 Munich, Germany
}

The axon guidance cue receptor DCC (deleted in colorectal cancer) plays a critical role in the organization of mesocorticolimbic pathways in rodents. To investigate whether this occurs in humans, we measured (1) anatomical connectivity between the substantia nigra/ventral tegmental area (SN/VTA) and forebrain targets, (2) striatal and cortical volumes, and (3) putatively associated traits and behaviors. To assess translatability, morphometric data were also collected in $D c c$-haploinsufficient mice. The human volunteers were $20 D^{+/-} C^{+/-}$ mutation carriers, $16 \mathrm{DCC}^{+/+}$relatives, and $20 \mathrm{DCC}^{+/+}$unrelated healthy volunteers (UHVs; 28 females). The mice were $11 \mathrm{Dcc}^{+/-}$and 16 wild-type C57BL/6J animals assessed during adolescence and adulthood. Compared with both control groups, the human $D C C^{+/-}$ carriers exhibited the following: (1) reduced anatomical connectivity from the SN/VTA to the ventral striatum $\left[D C C^{+/+}: p=0.0005\right.$, $r($ effect size $)=0.60$; UHV: $p=0.0029, r=0.48]$ and ventral medial prefrontal cortex $\left(D C C^{+/+}: p=0.0031, r=0.53 ; \mathrm{UHV}: p=0.034, r=\right.$ $0.35)$; (2) lower novelty-seeking scores $\left(D C C^{+/+}: p=0.034, d=0.82\right.$; UHV: $\left.p=0.019, d=0.84\right)$; and (3) reduced striatal volume $\left(D C C^{+/+}: p=0.0009, d=1.37 ; \mathrm{UHV}: p=0.0054, d=0.93\right)$. Striatal volumetric reductions were also present in $D c c^{+/-}$mice, and these were seen during adolescence ( $p=0.0058, d=1.09)$ and adulthood $(p=0.003, d=1.26)$. Together these findings provide the first evidence in humans that an axon guidance gene is involved in the formation of mesocorticolimbic circuitry and related behavioral traits, providing mechanisms through which $D C C$ mutations might affect susceptibility to diverse neuropsychiatric disorders.

Key words: axon guidance; brain morphometry; diffusion MRI; genetics; nicotine; personality

Significance Statement

Opportunities to study the effects of axon guidance molecules on human brain development have been rare. Here, the identification of a large four-generational family that carries a mutation to the axon guidance molecule receptor gene, $D C C$, enabled us to demonstrate effects on mesocorticolimbic anatomical connectivity, striatal volumes, and personality traits. Reductions in striatal volumes were replicated in $D C C$-haploinsufficient mice. Together, these processes might influence mesocorticolimbic function and susceptibility to diverse neuropsychiatric disorders.

\section{Introduction}

What guides the alignment of mesocorticolimbic pathways in humans? The processes are poorly understood, but the axon guidance

\footnotetext{
Received Nov. 14, 2017; revised March 29, 2018; accepted April 7, 2018

Author contributions: C.M., A.D., C.B., M.S., R.J., F.L., G.R., H.T., B.J.B., C.F., and M.L. designed research; D.E.V., A.C., C.M., C.E., D.A., and F.D. performed research; D.E.V., Y.Z., A.M., C.M., S.Z., K.D., and B.J.B. analyzed data; D.E.V., Y.Z., C.F., and M.L. wrote the paper.

This work was supported by the Canadian Institutes for Health Research (to M.L.; MOP-119543) and the National Institute on Drug Abuse (to C.F.; R01DA037911). We thank Jared Rowley and Dr. Pedro Rosa-Neto for their technical assistance.

${ }^{*}$ D.E.V. and Y.Z. contributed equally to this work.
}

molecule receptor DCC (deleted in colorectal cancer) might play an important role (Flores, 2011; Hoops and Flores, 2017). DCC is expressed throughout most of the nervous system during embryonic development (Gad et al., 1997; Livesey and Hunt, 1997; Harter et

The authors declare no competing financial interests.

Correspondence should be addressed to either of the following: Dr. Marco Leyton, Irving Ludmer Psychiatry Building, 1033 Pine Avenue West, Montreal, Quebec H3A 1A1, Canada, E-mail:marco.leyton@mcgill.ca; or Dr. Cecilia Flores, Douglas Mental Health University Institute, 6875 Boulevard LaSalle, Montreal, Quebec H4H 1R3, Canada, E-mail: cecilia.flores@mcgill.ca.

DOI:10.1523/JNEUROSCI.3251-17.2018

Copyright $\odot 2018$ the authors $\quad 0270-6474 / 18 / 384655-11 \$ 15.00 / 0$ 
Table 1. Participant characteristics

\begin{tabular}{|c|c|c|c|c|}
\hline & UHV & $D C C^{+/+}$relatives & $D C C^{+l-}$ & ANOVA or $\chi^{2} p$ value \\
\hline$N$ (Total) & 20 & 16 & 20 & \\
\hline$N($ MRI) & 19 & 12 & 18 & \\
\hline Age (mean $\pm S D)$ & $41.8 \pm 16.0$ years & $38.3 \pm 13.2$ years & $46.2 \pm 16.0$ years & $p=0.31$ \\
\hline Sex (male/female) & $11: 9$ & $6: 10$ & $11: 9$ & $p=0.50$ \\
\hline Handedness & 19 right, 1 left & 11 right, 3 left, 2 ambidextrous & 15 right, 4 left, 1 ambidextrous & $p=0.25$ \\
\hline Sensitivity to punishment (mean \pm SD) & $6.8 \pm 4.6(n=19)$ & $6.9 \pm 5.5(n=14)$ & $8.4 \pm 5.2(n=19)$ & $p=0.59$ \\
\hline Sensitivity to reward (mean $\pm S D$ ) & $9.7 \pm 3.8(n=20)$ & $8.1 \pm 3.1(n=14)$ & $9.4 \pm 4.6(n=19)$ & $p=0.48$ \\
\hline Novelty seeking (mean $\pm \mathrm{SD}$ ) & $104.8 \pm 12.3^{*}(n=15)$ & $104.2 \pm 11.2^{*}(n=13)$ & $94.9 \pm 11.2(n=18)$ & $p=0.03$ \\
\hline
\end{tabular}

Sample sizes, demographic characteristics, and personality traits for $\mathrm{DCC}^{+/-}$mutation carriers, $D C C^{+/+}$relatives, and UHVs. Asterisks $\left(^{*}\right)$ indicate $p \leq 0.05$ compared to $D C C^{+/-}$participants.

al., 2010) and continues to be expressed in adulthood in some regions, including the substantia nigra/ventral tegmental area (SN/ VTA), striatum, hippocampus, and cortex (Gad et al., 1997; Livesey and Hunt, 1997; Osborne et al., 2005; Grant et al., 2007; Harter et al., 2010; Manitt et al., 2010; Reyes et al., 2013).

Mice haploinsufficient for the Dcc gene develop diverse alterations to mesocorticolimbic anatomy and related behaviors during the adolescent expansion of mesocortical dopamine projections (Hoops and Flores, 2017). Dcc haploinsufficiency in dopamine neurons causes mesolimbic dopamine axons normally retained in the striatum to continue to grow to the medial prefrontal cortex (mPFC) throughout adolescence (Reynolds et al., 2018). As a consequence, adult Dcc-haploinsufficient mice have increased $\mathrm{mPFC}$ dopamine innervation and dopamine release (Grant et al., 2007; Manitt et al., 2011; Pokinko et al., 2015). This is coupled with decreased spine density, dendritic arbor complexity, and excitability of mPFC layer V pyramidal neurons (Grant et al., 2007; Manitt et al., 2013). In the nucleus accumbens (NAcc), these same processes lead to reduced dopamine innervation and amphetamine-induced dopamine release (Flores et al., 2005; Grant et al., 2007; Pokinko et al., 2015; Reynolds et al., 2018). Behaviorally, adult Dcc-haploinsufficient mice exhibit blunted stimulant drug-induced responses, including reductions in locomotor activity, sensorimotor gating, conditioned place preference, and intracranial self-stimulation (Flores et al., 2005; Grant et al., 2007; Kim et al., 2013; Reynolds et al., 2016).

In the present study, we tested whether DCC-haploinsufficient humans exhibit mesocorticolimbic connectivity alterations and associated behavioral traits similar to those identified in Dcc-heterozygous mice. The sample comprised a large four-generational Quebec family, half of whom are carriers for an autosomal dominant mutation that induces DCC haploinsufficiency (Srour et al., 2009, 2010). Within the family, a genome-wide linkage analysis identified a DCC frameshift mutation (NM_005215.3, c.1140 + 1G>A) resulting from abnormal skipping of exon 6 . This leads to a premature stop codon encoding a truncated DCC protein that fails to bind to its ligand, Netrin-1 (Srour et al., 2010).

To investigate alterations potentially associated with DCCrelated susceptibility to psychiatric pathology, we tested whether DCC-haploinsufficient humans, compared with $D C C$ wild-type family relatives and unrelated healthy volunteers (UHVs), exhibit (1) altered structural and functional connectivity between the midbrain and projection sites in the ventral striatum (VS) and $\mathrm{mPFC}$, and (2) a behavioral phenotype consistent with low striatal dopamine transmission comprising diminished noveltyseeking and reward-sensitivity traits, decreased substance use, and increased punishment sensitivity (Leyton et al., 2002; Frank et al., 2004). Finally, using a translational cross-species magnetic resonance imaging (MRI) approach, we tested whether these effects might be associated with alterations in striatal and cortical brain volume. Automated morphometric analyses were conducted in the DCC-haploinsufficient human volunteers and Dcchaploinsufficient C57BL/6 mice. The rodents were tested in both adolescence and adulthood to determine whether volumetric effects preceded or coincided with the previously demonstrated changes to dopamine neurons.

\section{Materials and Methods}

Human participants and data acquisition

Fifty-six volunteers participated in the study (28 males; age: $42.4 \pm 15.3$ years, 19-72 years old). Among them, 20 were DCC mutation carriers (DCC ${ }^{+/-}$; 11 males; age: $46.3 \pm 16.1$ years, $20-72$ years old), 16 were age-matched relatives without the $D C C$ mutation $\left(D C C^{+/+}\right.$; six males, $37.9 \pm 13.0$ years, $22-63$ years old), and 20 were UHVs ( 11 males; age: $42.2 \pm 15.4$ years, $19-60$ years old). Four participants were not interested in completing the neuroimaging procedures and three were physically unable to fit into the MRI scanner. Detailed information regarding the participants and the number who completed each task is provided in Table 1. A pedigree of the Quebec family is provided in Figure 1. Recruitment of family members was solely based on interest and safety. UHVs were all neurologically intact and free of current major psychiatric disorders, including substance-use disorders, except for one who met criteria for a possible mild mood disorder; excluding this individual did not change the results. All provided written informed consent to the study protocol, which was approved by the local research ethics committee.

Genotyping. All participants underwent genotyping either at assessment for the present study or previously (Srour et al., 2010). Genotyping was unavailable for one UHV and excluding this individual did not alter the findings. Coding exons and the exon-intron boundaries of the DCC gene were screened for mutations based on the sequence [NM_005215; UCSC (University of California, Santa Cruz) March 2006 Assembly hg18]. Primers were determined in a previous study of the family (Srour et al., 2010). PCR products were sequenced on the ABI 3700 Sequencer at the Genome Quebec Centre for Innovation according to the manufacturer's recommended protocol (Applied Biosystems). Sequences were aligned and analyzed using SeqMan 4.03 (DNAStar) and Mutation Surveyor v.3.1 (SoftGenetics).

Personality and substance-use measures. Participants completed questionnaires assessing novelty seeking and sensitivity to punishment and reward. Novelty-seeking traits were measured using Cloninger's 240-item Temperament and Character Inventory (De Fruyt et al., 2000). Sensitivity to punishment and reward were measured with the Sensitivity to Punishment and Sensitivity to Reward Questionnaire, a 48-item scale developed to assess temperamental correlates of Gray's hypothesized behavioral activation and inhibition systems (Caseras et al., 2003). In a structured interview, self-reported weekly current substance use (e.g., drinks, cannabis, and tobacco cigarettes, etc.), lifetime substance use, and age of onset were evaluated for alcohol, cigarettes, and cannabis. Other substances were measured but not evaluated statistically because the number of self-reported users was too low. These comprised amphetamine, cocaine, 3,4-methylenedioxymethamphetamine (MDMA), heroin, ketamine, gamma hydroxybutyrate (GHB), ephedrine, steroids, psilocybin, and lysergic acid diethylamide (LSD). 


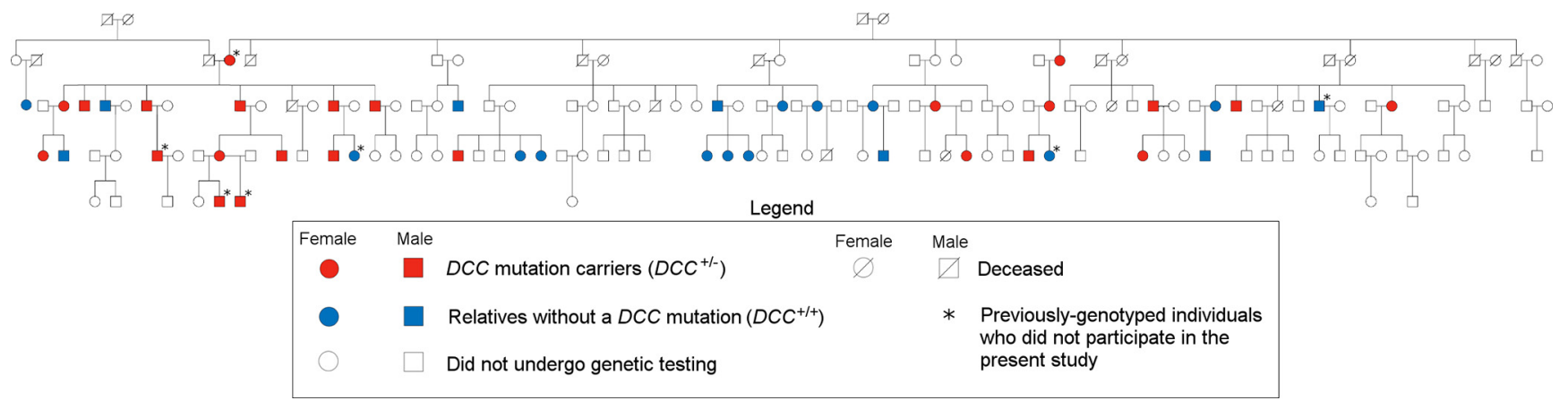

Figure 1. Pedigree of the Quebec family. Red indicates $\mathrm{DCC}^{+/-}$; blue indicates $\mathrm{DCC}^{+/+}$; white designates those who did not undergo genetic testing. Crossed lines designate deceased individuals. Squares are males; circles are females. * indicates previously genotyped (Srour et al., 2010) individuals who did not participate in the present study.

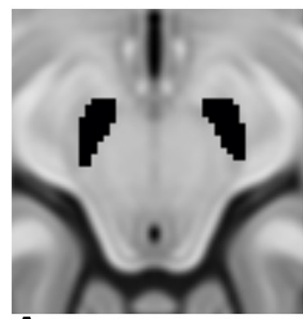

A SN/VTA: $z=-11$

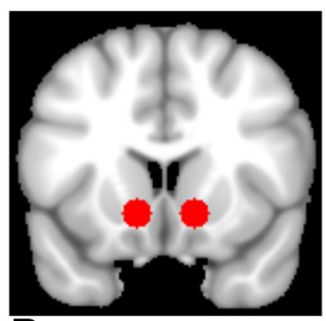

B vs: $y=14$
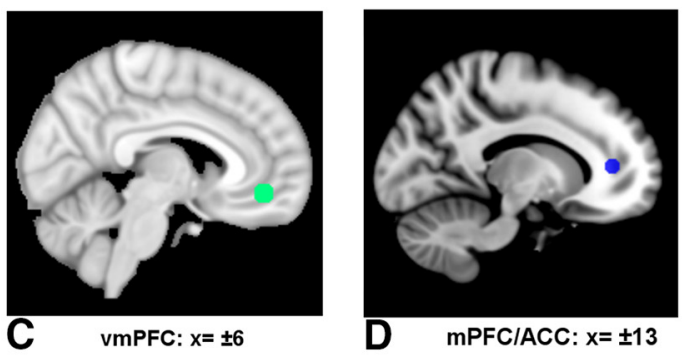

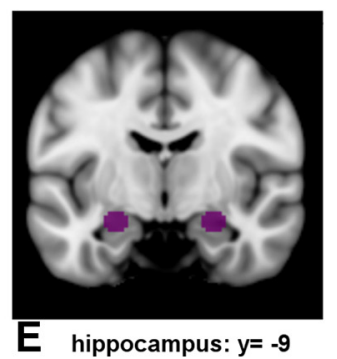

Figure 2. Depiction of human regions of interest. $A$, SN/VTA (black). $\boldsymbol{B}, \mathrm{VS}$ (red). C, vmPFC (green). D, mPFC/ACC (blue). E, Hippocampus (purple).

Human MRI. Participants underwent anatomical, diffusion-weighted, and resting-state functional MRI (rs-fMRI) acquisitions in a scanning session using a 3T Siemens Magnetom Trio MRI scanner (12-channel head coil). Forty-nine participants underwent diffusion tensor imaging (DTI) using a single-shot spin-echo echo-planar pulse sequence with multidirectional diffusion weighting [repetition time $(\mathrm{TR})=12 \mathrm{~s}$, echo time $(\mathrm{TE})=89 \mathrm{~ms} ; 90$ contiguous axial slices with an isotropic $2 \mathrm{~mm}$ resolution; field of view (FOV), $256 \times 256 \mathrm{~mm}^{2}$; matrix size, $128 \times 128$ with partial Fourier reconstructed to 6/8]. Diffusion weighting was distributed along 64 different directions using a $b$ value of $1000 \mathrm{~s} / \mathrm{mm}^{2}$. One additional volume with no diffusion weighting (i.e., $b=0$ ) was acquired in the beginning of the acquisition. Using a T1-weighted 3D magnetizationprepared rapid acquisition with gradient echo sequence [200 axial slices; inversion time $(\mathrm{TI})=0.9 \mathrm{~s} ; \mathrm{TR}=2.3 \mathrm{~s} ; \mathrm{TE}=2.98 \mathrm{~ms} ; \mathrm{FOV}, 256 \times 256$ $\mathrm{mm}^{2}$; flip angle, $9^{\circ}$; final voxel resolution: $1 \times 1 \times 1 \mathrm{~mm}$ ], a highresolution anatomical scan was also acquired for each participant.

Immediately after the DTI, participants underwent the rs-fMRI acquisition. Forty-three participants, including $17 \mathrm{DCC}^{+/-}, 12 \mathrm{DCC}^{+/+}$, and 14 UHV participants, completed resting-state scans. All participants were instructed to rest with their eyes closed, relax their minds, and remain as motionless as possible during the scanning. A total of 180 volumes, each covering the entire brain, including the cerebellum with 38 axial slices, were acquired using a gradient-echo echo planar imaging sequence $\left(\mathrm{TR}=2000 \mathrm{~ms} ; \mathrm{TE}=30 \mathrm{~ms}\right.$; FOV, $256 \times 256 \mathrm{~mm}^{2}$; matrix, $64 \times 64$; slice thickness, $4 \mathrm{~mm}$ with no gaps; flip angle, $\left.90^{\circ}\right)$. Slices were acquired in a descending and interleaved manner.

Human voxel-based morphometry analysis. Anatomical scans were preprocessed in SPM8 (www.fil.ion.ucl.ac.uk/spm/software/spm8) using the DARTEL (Diffeomorphic Anatomic Registration through Exponentiated Lie) and VBM8 toolbox (http://dbm.neuro.uni-jena.de/vbm8/). First, the structural MRI images were segmented into gray matter (GM), white matter (WM), CSF, bone, and soft tissue. The DARTEL algorithm registered these tissue segmentations back and forth with the default templates based on the ICBM152 brain, and finally generated population-specific tissue templates. GM and WM density images of all subjects were subsequently nonlinearly registered onto the corresponding template. In VBM8, all registered tissue images were modulated using the Jacobian determinants derived from the spatial normalization step and corrected for individual head size. The modulated GM and WM tissue images were then smoothed with an $8 \mathrm{~mm}$ full-width at halfmaximum (FWHM) Gaussian kernel.

The Harvard-Oxford subcortical atlas with a 25\% threshold (Desikan et al., 2006) was used to define four a priori selected regions: the caudate, putamen, accumbens, and hippocampus. The ventral mPFC (vmPFC) and $\mathrm{mPFC} /$ anterior cingulate cortex (mPFC/ACC) were defined by drawing a $6 \mathrm{~mm}$ sphere around the coordinates (vmPFC: $x= \pm 6, y=45$, $z=-9$; mPFC/ACC: $x= \pm 18, y=42, z=9$; as explained below).

Human connectivity seed and target regions. An SN seed mask was generated from a 7T MRI atlas of the basal ganglia based on highresolution MP2RAGE and FLASH (fast low-angle shot) scans (Keuken and Forstmann, 2015) available at https://www.nitrc.org/projects/atag. The entire region of the SN (Fig. $2 A$ ) was extracted from the probabilistic atlas with a threshold of $33 \%$ of the population (i.e., $\geq 10$ of 30 participants showing this nucleus) with an $\sim 300 \mathrm{~mm}^{3}$ volume in each hemisphere. Considering the low spatial resolution of our functional and diffusion data [ $4 \mathrm{~mm}$ isotropic for rs-fMRI and $2 \mathrm{~mm}$ for DTI], the seed might also cover part of the adjacent VTA. Here, we designated this seed region as the SN/VTA.

Target regions comprised the VS and vmPFC, defined by drawing a 6 $\mathrm{mm}$ sphere around the peak coordinates (VS: $x= \pm 12, y=15, z=-6$; vmPFC: $x= \pm 6, y=45, z=-9$ ), acquired from a recent fMRI metaanalysis of subjective value (Bartra et al., 2013; Fig. 2 B,C). Other regions, including the hippocampus $(x= \pm 24, y=-9, z=-15)$ and the mPFC/ ACC $(x= \pm 18, y=42, z=9)$, identified from the whole-brain functional connectivity analysis, were also included in the anatomical and functional connectivity analyses (Fig. 2D,E).

Human diffusion-weighted imaging preprocessing. The diffusion MR data were preprocessed using the FMRIB's Diffusion Toolbox [FMRIB (Oxford Centre for Functional MRI of the Brain) Software Library (FSL) version 5.0; http://fsl.fmrib.ox.ac.uk/fsl/fslwiki/FSL], including eddy current correction, calculation of the principal directions in diffusion tensors, and estimation of the probabilistic distribution of fiber orientations. Specifically, motion artifacts and eddy current distortions were corrected by using affine registration of diffusion-weighted images to the nondiffusion-weighted images $\left(b=0 \mathrm{~s} / \mathrm{mm}^{2}\right)$. Then, a diffusion tensor model was fitted for each voxel to estimate the principal fiber directions 
and a fractional-anisotropy (FA) and mean-diffusivity (MD) map was calculated. Next, the probabilistic distribution of fiber orientations was estimated using FSL's BEDPOSTX with a maximum of two fiber directions per voxel (Behrens et al., 2007). The skull-stripped T1-weighted image from each participant was then linearly registered into the diffusion space by using rigid-body alignment of the anatomical image to the FA image. This coregistered T1-weighted image was further nonlinearly registered to the ICBM152 brain template (http://www.bic.mni.mcgill.ca/ServicesAtlases/ICBM152NLin2009) using FNIRT (FMRIB's Nonlinear Image Registration Tool) from the FSL package. The reverse transformation was then obtained and used to nonlinearly register the seed region from MNI standard space to native diffusion space.

Human anatomical connectivity profile. We mapped the anatomical connectivity profile of the SN/VTA by performing probabilistic tractography with 10,000 streamline fibers per voxel within the seed region using FSL's PROBTRACKX. The number of fibers passing through each target region represents the strength of connectivity between the seed and target region. The resulting connectivity maps were first normalized by the size of seed region and total number of streamlines (i.e., 10,000) to generate the relative tracing strength from the seed to the rest of the brain. The resulting individual tractograms were combined to generate a population map of the major fiber projections from the SN/VTA. The relative connection probability from the SN/VTA to each target area was then calculated by averaging the tractography values of the population fiber-tract maps.

In addition to the tractography analysis, we also investigated group differences in FA and MD in the whole-brain WM skeletons, including tracts between the SN/VTA and the target regions, using Tract-Based Spatial Statistics (TBSS) from FSL (Smith et al., 2006). Threshold-free cluster enhancement was used to correct for multiple comparisons (Smith and Nichols, 2009). The mean FA and MD values within the SN/VTA and other target areas were also calculated.

Human resting-state functional connectivity preprocessing. The rs-fMRI datasets were preprocessed using a revised script based on the 1000 Functional Connectome Project (www.nitrc.org/projects/fcon_1000; Biswal et al., 2010) using both FSL and AFNI (Automated Functional NeuroImaging; http://afni.nimh.nih.gov/afni). The preprocessing steps included the following: (1) discarding the first 10 volumes in each scan series for signal equilibration, (2) performing slice timing correction and motion correction, (3) removing the linear and quadratic trends, (4) bandpass temporal filtering $(0.01 \mathrm{~Hz}<f<0.08 \mathrm{~Hz})$, (5) spatial smoothing using a $6 \mathrm{~mm}$ FWHM Gaussian kernel, (6) performing nuisance signal regression (including WM, CSF, the global signal, and six motion parameters), and (7) resampling into MNI space with the concatenated transformations, including rigid transformation from the mean functional volume to the individual anatomical volume via FLIRT (FMRIB's Linear Image Registration Tool; Jenkinson and Smith, 2001) followed by spatial normalization of the individual anatomical volume to the MNI152 brain template (3 mm isotropic resolution) using FNIRT (Andersson et al., 2007). Finally, a four-dimensional time-series dataset in standard MNI space with $3 \mathrm{~mm}$ isotropic resolution was obtained for each participant after preprocessing.

Human resting-state functional connectivity. The mean time course of the seed SN/VTA was extracted individually to calculate whole-brain functional connectivity using Pearson's correlation along with normalization by Fisher's $z$ transform. As a result, a $z$-score connectivity map was generated for each individual. To detect the effect of the DCC mutation on projections from the SN/VTA, a two-sample $t$ test in SPM was performed on these connectivity maps $\left(D C C^{+/-}\right.$vs $\left.D C C^{+/+}\right)$and additionally corrected for multiple comparisons using false discovery rate (FDR) corrected $p=0.05$ with cluster size $\geq 540 \mathrm{~mm}^{3}$. The functional connectivity between the SN/VTA and our predefined target areas (including the VS and vmPFC) were also calculated using Pearson's correlation and transformed into $z$ scores.

Experimental design and statistical analyses of human data. Group differences in personality traits, substance use, GM volume, and connectivity measures were examined with $\chi^{2}$ analyses and one-way ANOVAs followed by $t$-test planned comparisons, comparing each control group to the $D C C^{+/-}$group using both MATLAB15b for Linux and Graphpad
Prism 7 for Windows. For nonparametric data, Kruskal-Wallis followed by Mann-Whitney $U$ tests were conducted, comparing each control group to the $D C C^{+/-}$group. Effect sizes were computed, specifically Cohen's $d$ for parametric pairwise comparisons and $r=\frac{Z}{\sqrt{N}}$ for nonparametric pairwise comparisons (Fritz et al., 2012).

To investigate associations between SN/VTA connectivity and personality traits, we performed Pearson and Spearman partial correlation analyses, as appropriate to the data, between both functional and anatomical connectivity and novelty seeking, sensitivity to punishment, sensitivity to reward, and lifetime substance use. Age and gender were used as covariates of no interest. For Pearson correlation analyses, outliers were removed before calculating the correlation coefficients, which were identified based on robust regression weights (Rousseeuw and Hubert, 2011). Additionally, for lifetime substance use, log transformations were performed before the correlations due to a large nonlinear range in the values. Participants who reported zero or one current or lifetime substance use were removed from these group and correlation analyses because these values skewed the distributions.

\section{Dcc-haploinsufficient mice}

Male Dcc-haploinsufficient mice were originally obtained from Dr. Susan Ackerman. They were maintained on a C57BL/6J (BL/6) background and bred with female BL/6 mice from The Jackson Laboratory. Volumetric differences were characterized between male Dcc-haploinsufficient $(n=11)$ and wild-type $(n=16)$ mice during adolescence [postnatal day (P) $33 \pm 2$ ], and, again, in the same animals, in adulthood (P75 \pm 15$)$. Mice were kept on a $12 \mathrm{~h}$ light/dark cycle with ad libitum access to food and water. They were weaned at P20 and housed with same-sex littermates. In Dcc-haploinsufficient mice, the Dcc gene was inactivated using homologous recombination by the insertion of a neomycin resistance cassette into exon 3 , which encodes most of the second Ig-like domain of the protein. The proper targeting of the gene and complete loss of DCC expression were validated by Southern and Western blot analyses, respectively (Fazeli et al., 1997). Mouse genotypes were verified by PCR amplification of genomic DNA at an annealing temperature of $54^{\circ} \mathrm{C}$ for 30 cycles with the primers DCC code (GGT CAT TGA GGT TCC TTT), DCC reverse (AAG ACG ACC ACA CGC GAC), and DCC Neo (TCC TCG TGC TTT ACG GTA TC). All experiments and procedures were performed in accordance with the guidelines of the Canadian Council of Animal Care and the McGill University/Douglas Mental Health University Institute Animal Care Committee.

Mouse MRI acquisition. MRI was performed using a 7 tesla Bruker BioSpec 70/30 USR at the Douglas Brain Imaging Center (Montreal, Canada) using a transmit circularly polarized resonator and a dedicated mouse brain receive-only circularly polarized surface coil (Bruker). Mice were immobilized in a prone position on a water-heated mat. Anesthesia was induced with 5\% isoflurane for 2 min and maintained with $2 \%$ isoflurane for the duration of the experiment. Anatomical images of brains within skulls were acquired using the standard Bruker 3DTrueFISP pulse sequence with the following parameters: $\mathrm{TE}=2.6 \mathrm{~ms}$; $\mathrm{TR}=5.2 \mathrm{~ms}$; number of excitations, 2 ; effective bandwidth, $50,000 \mathrm{~Hz}$; FOV, $1.80 \times 1.80 \times 0.9 \mathrm{~cm}$; matrix size, $128 \times 128 \times 64$; final spatial resolution; $141 \mu \mathrm{m}$ isotropic voxels. To reduce banding artifacts, eight radio frequency phase advance values were used: 180, 0, 90, 270, 45, 225, 135 , and $315^{\circ}$. These resulted in 16 averages overall. Final images were root mean square averages of these phase advances. The total scan time for each animal was $<40 \mathrm{~min}$.

Segmentation of regions of interest. The a priori selected regions of interest were four mesocorticolimbic terminal regions: the $\mathrm{mPFC}$, dorsal striatum, NAcc, and hippocampus (Fig. 3A-C). Within the inner layers of the $\mathrm{MPFC}$, three regions were analyzed: the cingulate 1 , prelimbic, and infralimbic cortices. An anatomical template was generated from the nonlinear average of the 54 scans. A single rater performed manual segmentation of the structures of interest on the group template using the Display software package (http://www.bic.mni.mcgill.ca/software/Display/ Display.html; Montreal Neurological Institute, Montreal, Canada). Structures were delineated in the coronal orientation slice by slice while comparing the other two orientations and the adjacent slices to the Mouse 


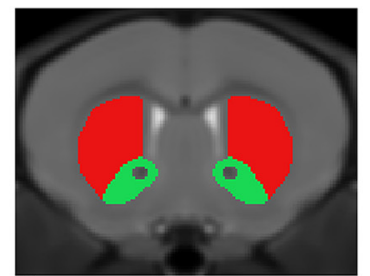

A

Striatum

$y=186$

Dorsal striatum (red)

Nucleus accumbens (green)

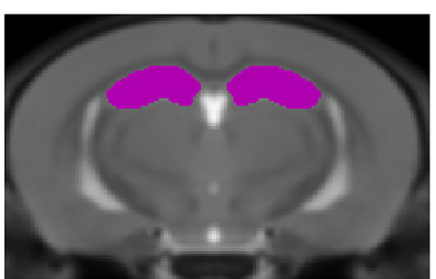

B Hippocampus (purple) $y=136$

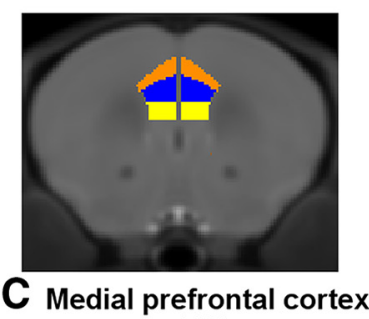

$y=195$

Cingulate-1 (orange)

Prelimbic (blue)

Infralimbic (yellow)

Figure 3. Depiction of mouse regions of interest. $\boldsymbol{A}$, Striatum including the NAcc (green) and dorsal striatum (red). B, Hippocampus (purple). C, Cingulate-1 (orange), prelimbic (blue), and infralimbic (yellow) mPFC subregions.

Brain Atlas (Paxinos and Franklin, 2004). Because the template was symmetric, tracings of the left hemisphere of the template brain were flipped to the right hemisphere. The third and lateral ventricles were segmented first to define the boundaries of the dorsal striatum and NAcc. After each structure was labeled, its boundaries were checked again and corrections were made in reference to all three orientations. The volumes of each structure were determined for every animal via fully automated, volume-based morphometry using NIGHTWING software (Biospective).

Experimental design and statistical analyses of mouse data. Differences in volume were analyzed using two-way ANOVAs with genotype and age as between-group and within-group variables, respectively. Statistical analyses were performed using GraphPad Prism 7 for Windows.

\section{Results}

\section{Human participant characteristics}

The groups were well matched for age, sex, and handedness (Table 1). As hypothesized, the novelty-seeking data analysis yielded a main effect of group $\left(F_{(2,43)}=3.74, p=0.032\right)$ reflecting decreased scores among $D C C^{+/-}$participants, compared with the $D C C^{+/+}$relatives $\left[T_{(43)}=2.19, p=0.034\right.$, effect size $\left.(d)=0.82\right]$ and UHVs $\left[T_{(43)}=2.44, p=0.019\right.$, effect size $(d)=0.84$; Fig. $\left.4 A\right]$. Intriguingly, $D C C^{+/-}$participants, compared with $D C C^{+/+}$relatives, also reported significantly lower lifetime cigarette smoking $[U=17, p=0.026$, effect size $(r)=0.51]$ and trends for decreased current cigarette use $\left[T_{(11)}=1.87, p=0.089\right.$, effect size $\left.(d)=1.04\right]$ as well as a later age of onset for cigarette use $\left[T_{(21)}=2, p=0.059\right.$, effect $\operatorname{size}(d)=0.83$; Fig. $4 B-D$ ]. Tobacco use in the $D C C^{+/}$participants did not differ from tobacco use in the UHVs (age of onset: $T_{(18)}=$ $1.27, p=0.22$; current use: $T_{(7)}=0.98, p=0.36$; lifetime use: $U=48$, $p=0.94)$, but this was not unexpected given that their stricter selection criteria included an absence of tobacco and other substance-use problems (see Human participants and data acquisition). Indeed, compared with $D_{C C}^{+/+}$relatives, the UHVs also exhibited significantly reduced lifetime use $(U=15, p=0.046)$ and increased age of onset $\left(T_{(19)}=2.77, p=0.012\right)$ of cigarette smoking. There were no statistically significant group effects for sensitivity to punishment, sensitivity to reward, alcohol use, or cannabis use.

\section{Human anatomical connectivity}

Main effects of group were found for anatomical connectivity between the SN/VTA seed and its target regions, the VS $\left(\chi_{(2)}^{2}=\right.$ 13.46, $p=0.0012)$ and $\operatorname{vmPFC}\left(\chi_{(2)}^{2}=8.72, p=0.013\right.$; Fig. $5 A, B)$. These effects reflected connectivity reductions in $\mathrm{DCC}^{+/-}$ carriers compared with both control groups; i.e., compared with $D_{C C}^{+/+}$[VS: $U=30, p=0.0005$, effect size $(r)=0.60$; vmPFC: $U=40, p=0.0031$, effect size $(r)=0.53$ ] and UHV [VS: $U=75$, $p=0.0029$, effect size $(r)=0.48$; vmPFC: $U=101.5, p=0.034$, effect size $(r)=0.35]$. Exploratory analyses identified a negative correlation between SN/VTA-hippocampus anatomical connectivity and lifetime cannabis $(\rho=-0.44, p=0.019$; Fig. $5 C)$, though this association was not predicted a priori.

A main effect of group was detected for FA in the hippocampus $\left(F_{(2,46)}=3.66, p=0.034\right)$, such that FA was reduced among $D C C^{+/-}$carriers compared with $D C C^{+/+}$relatives $\left(T_{(46)}=2.70\right.$, $p=0.0096$, effect size $(d)=1.02$ ) but not compared with UHV $\left(T_{(46)}=1.32, p=0.19\right.$, effect size $(d)=0.46$; Fig. $\left.5 D\right)$. To investigate whole-brain group differences in FA and MD, TBSS was performed among $D C C^{+/-}$carriers, $D C C^{+/+}$relatives, and UHVs. No significant group alterations in FA or MD skeletons were detected. Similarly, no significant group differences were detected in mean FA (all $p$ 's $\geq 0.16$ ) or mean diffusivity (all $p$ 's $\geq$ 0.26 ) within the SN/VTA, VS, vmPFC, or mPFC/ACC.

\section{Human functional connectivity}

The functional connectivity analyses did not yield statistically significant main effects of group for the SN/VTA with the a priori target sites. However, exploratory whole-brain analyses tentatively identified other group differences within the $\mathrm{DCC}^{+/-}$family (FDR corrected $p<0.05$; cluster size, $\geq 540 \mathrm{~mm}^{3}$ ), including decreased functional connectivity from the SN/VTA seed to the left $\mathrm{mPFC} / \mathrm{ACC}\left[T_{(27)}=5.02, \mathrm{p}_{\mathrm{FDR}}=0.014\right.$, effect size $(d)=1.93$; peak: $x=-18, y=42, z=9]$ and increased functional connectivity from the SN/VTA to the left hippocampus $\left[T_{(27)}=4.74\right.$, $\mathrm{p}_{\mathrm{FDR}}=0.047$, effect size $(d)=1.82$; peak: $x=-24, y=-9, z=$ $-15)$ in $D C C^{+/-}$participants, compared with $D C C^{+/+}$relatives (Table 2).

\section{Human morphometry}

Main effects of group were detected in the putamen $\left(F_{(2,46)}=\right.$ $7.35, p=0.0017)$, reflecting reduced volume in $D C C^{+/-}$carriers compared with both control groups $\left[D C C^{+/+}: T_{(46)}=3.54, p=\right.$ 0.0009 , effect size $(d)=1.37$; UHV: $T_{(46)}=2.92, p=0.0054$, effect size $(d)=0.93$; Fig. 6A]. No significant volumetric alterations between groups were detected in the NAcc, caudate nucleus, or hippocampus (Fig. 6B-D).

A significant main effect of group was also observed in the $\operatorname{vmPFC}\left(F_{(2,46)}=3.59, p=0.036\right)$, with increased volume among $D_{C C}{ }^{+/-}$carriers compared with UHVs $\left[T_{(46)}=2.53, p=0.015\right.$, effect size $(d)=0.94]$, but there were no differences between $D C C^{+/-}$carriers and $D C C^{+/+}$relatives $\left[T_{(46)}=0.36, p=0.72\right.$, effect size $(d)=0.12$; Fig. $6 E]$. In comparison, a significant main effect of group was detected in the mPFC/ACC $\left(F_{(2,46)}=4.87\right.$, $p=0.012$ ), a region detected in the functional connectivity whole-brain analysis, with the $D C C^{+/-}$carriers exhibiting signif- 
A

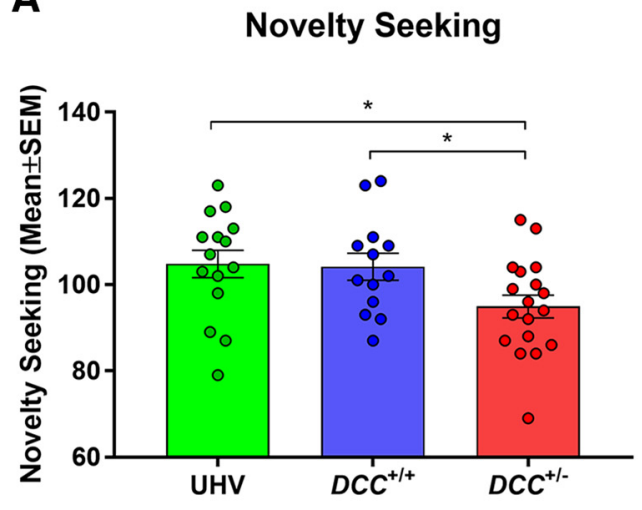

C

Cigarettes: Current Use

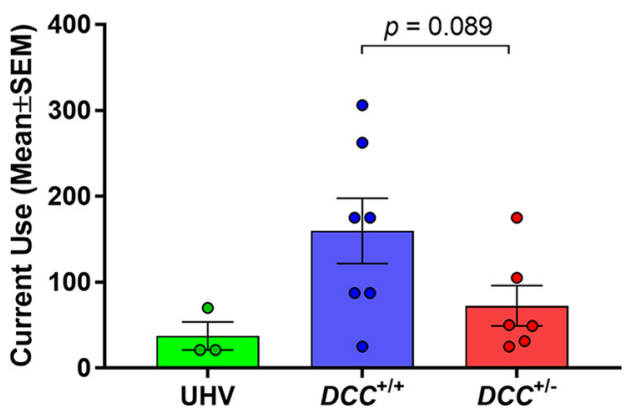

B

\section{Cigarettes: Age of Onset}

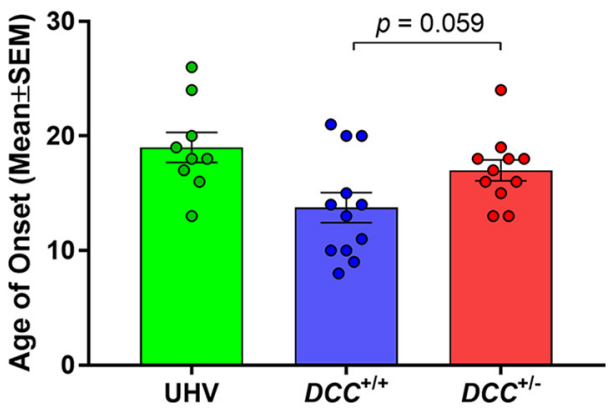

D

Cigarettes: Lifetime Use

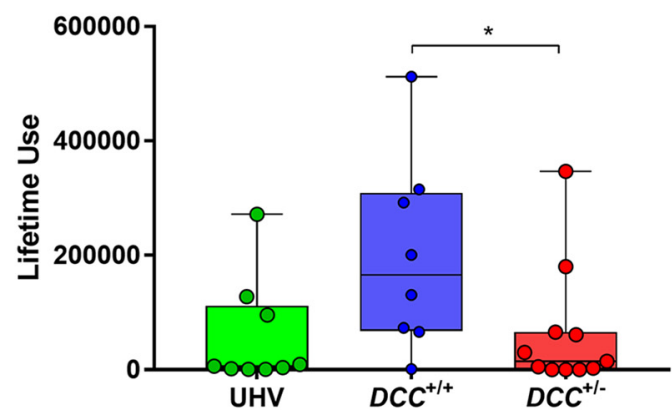

Figure 4. Personality traits and cigarette use. $\boldsymbol{A}-\boldsymbol{D}$, Group differences in $(\boldsymbol{A})$ novelty seeking, and three measures of cigarette smoking: $(\boldsymbol{B})$ age of onset, $(\boldsymbol{C})$ current weekly use, and $(\boldsymbol{D})$ lifetime use. Because the UHV selection criteria were stricter, excluding on the basis of psychiatric disorders including tobacco and other substance-use disorders, they were excluded from the cigarette analyses. ${ }^{*} p \leq 0.05$.

A

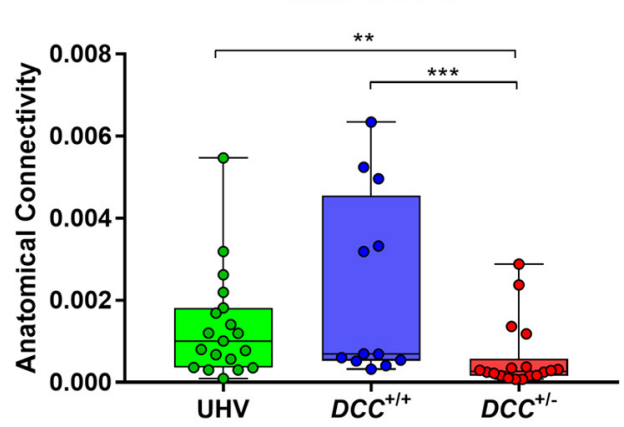

C

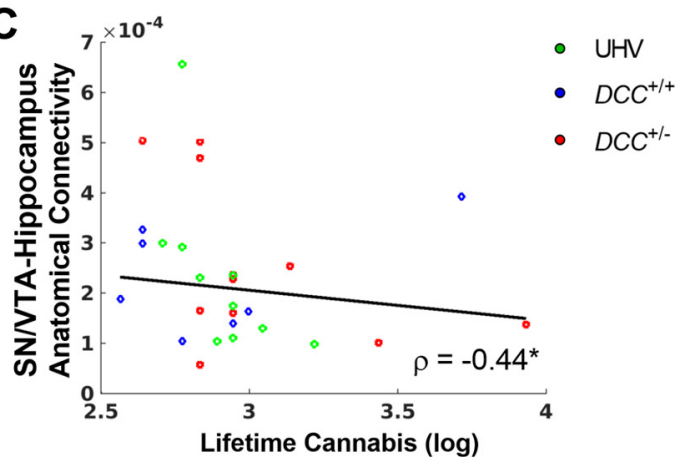

B

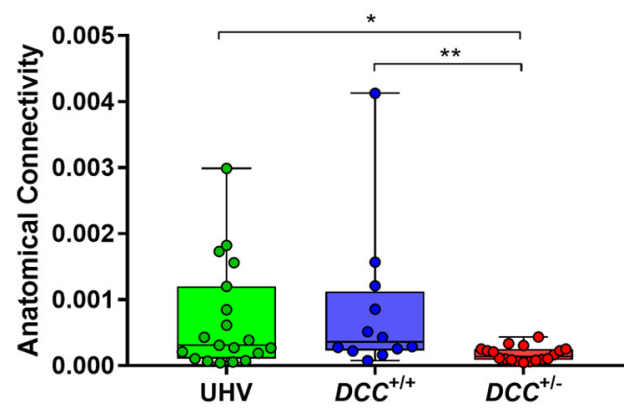

D

Hippocampus

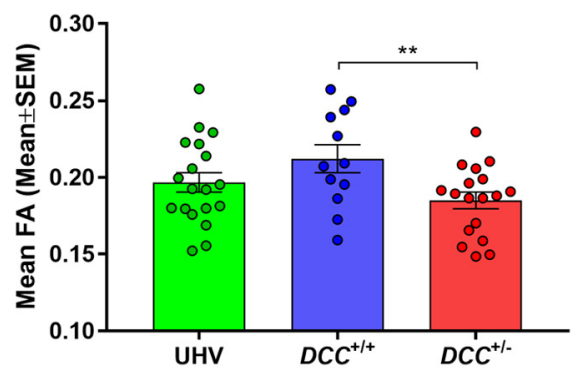

Figure 5. DTI. $\boldsymbol{A}, \boldsymbol{B}$, Group differences in anatomical connectivity with seed in SN/VTA and targets in ( $\boldsymbol{A})$ VS and (B) vmPFC. C, SN/VTA- hippocampus anatomical connectivity is negatively correlated with lifetime cannabis use. $\rho=-0.44^{*}$. D, Mean FA in the hippocampus is reduced in $D C C^{+/-}$carriers. Red circles are $D C C^{+/-}$carriers, blue circles are $D C C^{+/+}$relatives, and green circles are UHVs. ${ }^{*} p \leq 0.05,{ }^{* *} p \leq 0.01,{ }^{* * *} p \leq 0.001$. 
Table 2. Whole-brain functional connectivity differences between $\mathrm{DCC}^{+/-}$carriers and $\mathrm{DCC}^{+/+}$relatives, using the SN/VTA seed

\begin{tabular}{|c|c|c|c|c|c|c|c|c|c|}
\hline Contrasts & Hemisphere & Brain region & Cluster-size $\left(\mathrm{mm}^{3}\right)$ & Tscore & $P$ value FDR-corrected & Cohen's D & $x$ & $y$ & $z$ \\
\hline \multirow[t]{3}{*}{$\mathrm{DCC}^{+/-}>\mathrm{DCC}^{+/+}$} & Left/right & Inferior temporal gyrus & 1188 & 5.55 & 0.014 & 2.14 & 45 & -12 & -39 \\
\hline & Left/right & Superior frontal gyrus/middle frontal gyrus & 1755 & 5.10 & 0.014 & 1.96 & 18 & 63 & 30 \\
\hline & Left & Hippocampus & 540 & 4.74 & 0.047 & 1.82 & -24 & -9 & -15 \\
\hline \multirow[t]{3}{*}{$D C C^{+/-}<D C C^{+/+}$} & Left & $\mathrm{mPFC} / \mathrm{ACC}$ & 729 & 5.02 & 0.014 & 1.93 & -18 & 42 &. \\
\hline & Left/right & Superior parietal lobule/inferior parietal lobule & 972 & 4.75 & 0.047 & 1.83 & 21 & -75 & 51 \\
\hline & Right & Precentral gyrus & 567 & 4.69 & 0.047 & 1.81 & 3 & -24 & 72 \\
\hline
\end{tabular}

$\overline{D C C^{+/-}}>D C C^{+/+}$, Increased connectivity among $D C C^{+/-}$carriers compared to $D C C^{+/+}$carriers. $D C C^{+/-}<D C C^{+/+}$, Decreased connectivity among $D C C^{+/-}$carriers compared to $D C C^{+/+}$carriers. $p$ values are FDR corrected. Cluster size, $\geq 540 \mathrm{~mm}^{3}$.

A

Putamen

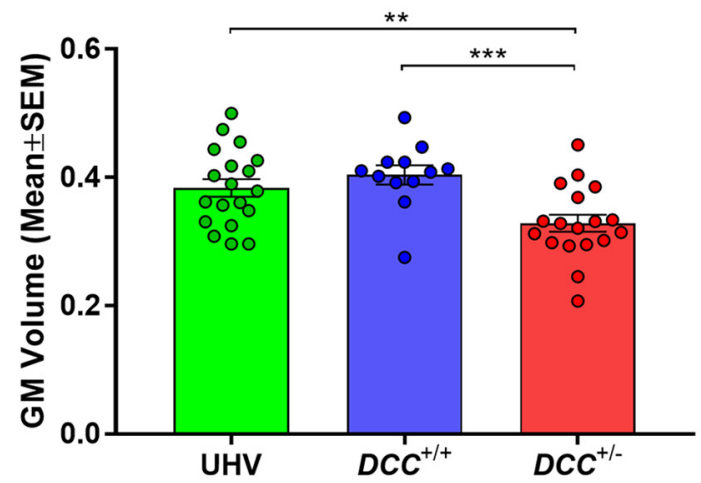

C

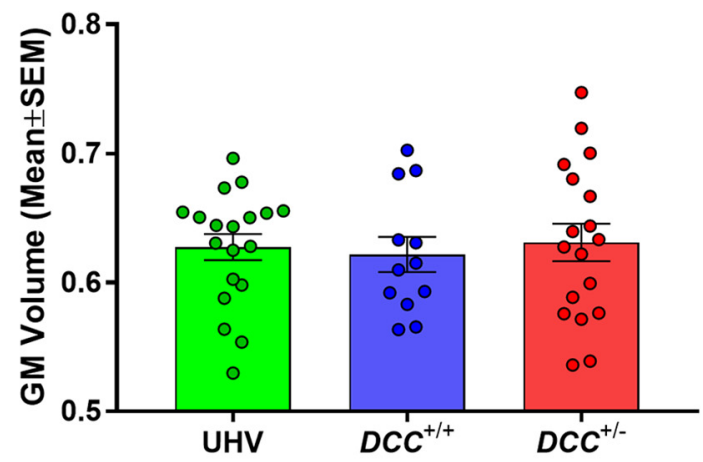

E

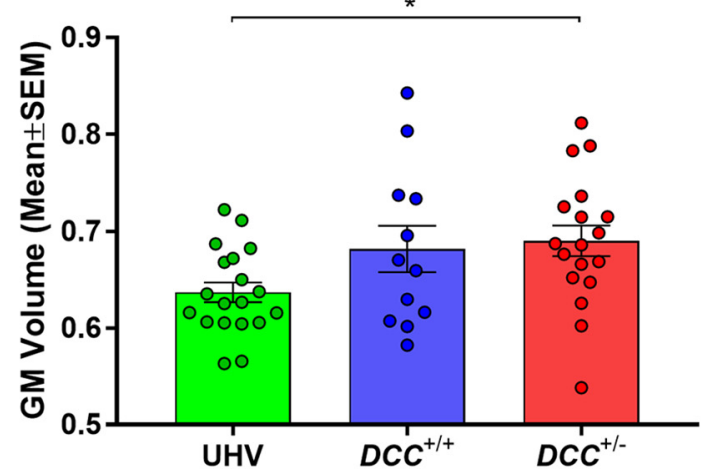

B

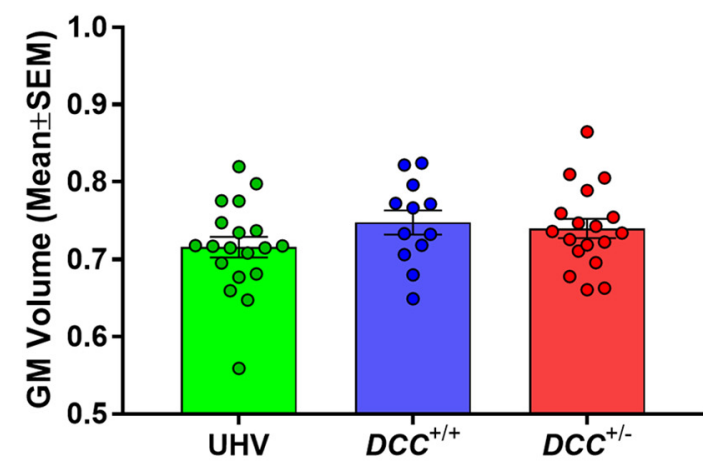

D

Hippocampus

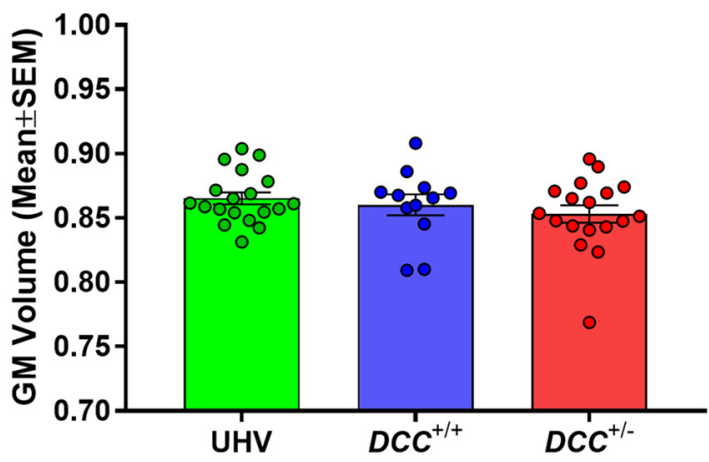

F
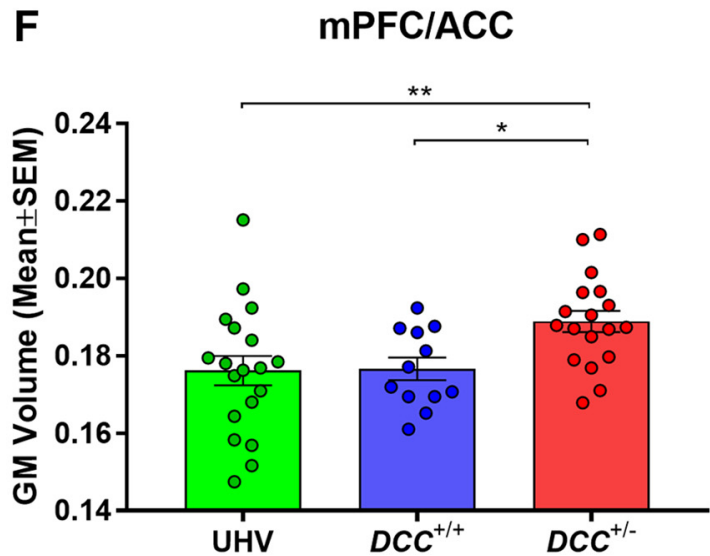

Figure 6. Human morphometry. Regional GM volume in $D C C^{+/-}$carriers, $D C C^{+/+}$relatives, and UHVs. $A-F$, Targets identified in whole-brain voxel-based morphometry and regions of interest comprised the $(\boldsymbol{A})$ putamen, $(\boldsymbol{B})$ nucleus accumbens $(\mathrm{NACc}),(\boldsymbol{C})$ caudate nucleus, $(\boldsymbol{D})$ hippocampus, $(\boldsymbol{E})$ vmPFC, and $(\boldsymbol{F}) \mathrm{mPFC} / \mathrm{ACC} .{ }^{*} p \leq 0.05,{ }^{* *} p \leq 0.01,{ }^{* * *} p \leq 0.001$. 
A
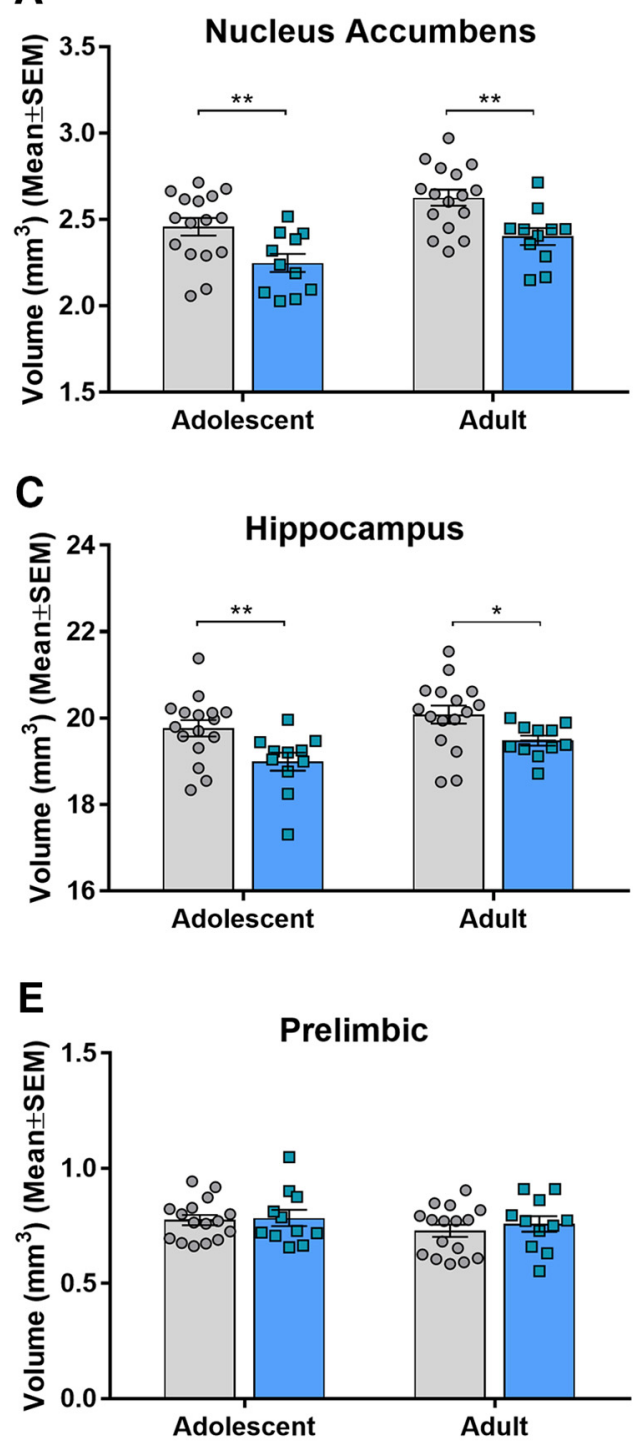

B

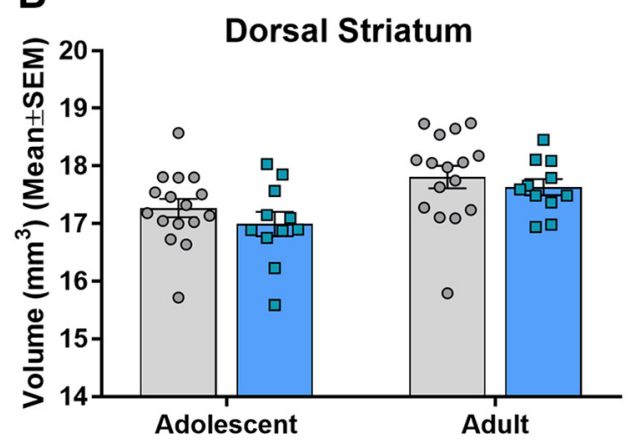

D
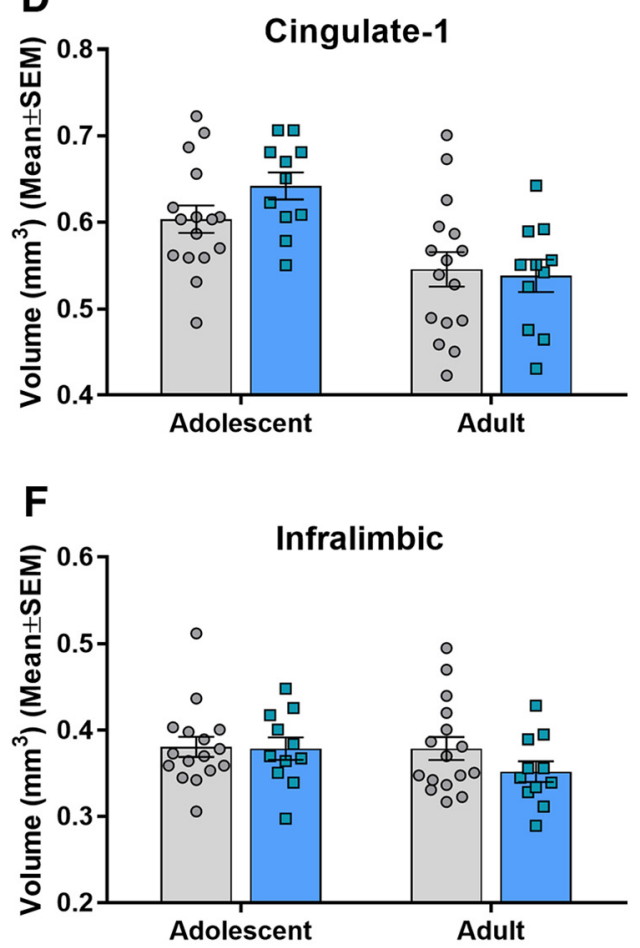

- Wild-type

ㅁ $\mathrm{DCC}^{+/-}$

Figure 7. Mice morphometry. Regional brain volumes in Dcc-haploinsufficient and wild-type mice, measured in adolescence and again, in the same animals, in adulthood. $\boldsymbol{A}-\boldsymbol{F}$, Regions of interest comprised the $(\boldsymbol{A})$ nucleus accumbens $(\mathrm{NAcc}),(\boldsymbol{B})$ dorsal striatum, $(\boldsymbol{C})$ hippocampus, and three subregions of the mPFC: (D) cingulate-1, $(\boldsymbol{E})$ prelimbic, and $(\boldsymbol{F})$ infralimbic. ${ }^{*} p \leq 0.05$, ${ }^{* *} p \leq$ 0.01 .

icantly increased volume, compared with both $D C C^{+/+}$relatives $\left[T_{(46)}=2.43, p=0.019\right.$, effect size $\left.(d)=1.10\right]$ and UHVs $\left[T_{(46)}=\right.$ 2.85, $p=0.0065$, effect size $(d)=0.88$; Fig. $6 F]$.

\section{Mouse morphometry}

The two-way ANOVA of NAcc volumes yielded main effects of genotype and age without a genotype $\times$ age interaction $\left(F_{(1,25)}=\right.$ $0.04, p=0.85)$. Compared with wild-type mice, Dcc-haploinsufficient mice exhibited reduced NAcc volumes $\left(F_{(1,25)}=12.66\right.$, $p=0.0015)$, and this was apparent both at adolescence $\left[T_{(50)}=\right.$ $2.88, p=0.0058$, effect size $(d)=1.09]$ and at adulthood $\left[T_{(50)}=\right.$ 3.09, $p=0.003$, effect size $(d)=1.26$ ]. The main effect of age reflected increased NAcc volumes in adulthood, relative to adolescence, for both genotypes $\left(F_{(1,25)}=16.61, p=0.0004\right.$; Fig. $\left.7 A\right)$. There was not a significant effect of genotype in the dorsal stria- tum $\left(F_{(1,25)}=0.84, p=0.37\right)$, but there was an effect of age $\left(F_{(1,25)}=46.77, p<0.0001\right)$, reflecting increased volume in adulthood, relative to adolescence (Fig. $7 B$ ).

As with the NAcc, a volumetric reduction in the hippocampus was detected among Dcc-haploinsufficient mice, relative to wildtype mice, as evidenced by a main effect of genotype $\left(F_{(1,25)}=6.77\right.$, $p=0.015)$, with significant effects at adolescence $\left[T_{(50)}=2.78, p=\right.$ 0.0077 , effect size $(d)=1.05]$ and adulthood $\left[T_{(50)}=2.17, p=\right.$ 0.035 , effect size $(d)=0.88$. Hippocampal volumes also exhibited a main effect of age $\left(F_{(1,25)}=21.55, p<0.0001\right)$, whereby volumes were increased in adulthood, relative to adolescence, for both genotypes. The genotype $\times$ age interaction was not significant $\left(F_{(1,25)}=0.97, p=0.33\right.$; Fig. $\left.7 C\right)$.

There were no statistically significant effects of genotype in the cingulate-1, prelimbic, or infralimbic regions of the mPFC. How- 
ever, main effects of age were identified in the cingulate- 1 cortex where volumes were reduced in adulthood, relative to adolescence, for both genotypes $\left(F_{(1,25)}=28.56, p<0.0001\right)$. Similar trends for effects of age were detected in the prelimbic $\left(F_{(1,25)}=\right.$ $3.69, p=0.066)$ and infralimbic $\left(F_{(1,25)}=3.55, p=0.071\right)$ cortices (Fig. 7D-F).

\section{Discussion}

The study's primary findings are that humans who are haploinsufficient for the axon guidance molecule receptor gene DCC exhibited decreased mesocorticolimbic anatomical connectivity, decreased striatal volume, lower novelty-seeking personality-trait scores, and, more tentatively, less use of at least one addictive substance, cigarettes. Volumetric reductions seen in the striatum were paralleled by strikingly similar findings in Dcc-haploinsufficient mice.

\section{Alterations in human mesocorticolimbic connectivity}

To our knowledge, the present study provides the first evidence that DCC-haploinsufficient humans have decreased anatomical connectivity between the SN/VTA and forebrain projection sites. This finding is consistent with results from a recent DTI study of a single individual with homozygous $D C C^{-/-}$mutations. That study identified broad disorganization and axon reduction, including a decrease in anterior-posterior fibers (Jamuar et al., 2017). Of greater relevance for the current study, the more extensive literature with DCC-deficient mice has identified direct evidence of mesocorticolimbic-specific connectivity disturbances. During adolescence, DCC receptors in mesolimbic dopamine neurons promote their targeting in the NAcc, preventing them from growing ectopically to the mPFC (Manitt et al., 2011, 2013; Reynolds et al., 2018). In conditional Dcc haploinsufficient mice, the mesolimbic dopamine neurons are rerouted to the cingulate 1 and prelimbic portions of the pregenual mPFC (Manitt et al., 2011; Reynolds et al., 2018), concomitantly reduced dopamine varicosities in the NAcc (Reynolds et al., 2018), and diminished amphetamine-induced NAcc dopamine release (Flores et al., 2005; Grant et al., 2007). The effects of Dcc haploinsufficiency on nondopamine corticolimbic-midbrain connectivity have not been explored in detail.

Functional connectivity changes between the SN/VTA and its targets in the mPFC/ACC and hippocampus were also identified when contrasting $\mathrm{DCC}^{+/-}$carriers and their $D C C^{+/+}$relatives. However, these same alterations were not observed between $D C C^{+/-}$ carriers and UHVs. This could reflect the fact that the $D C C^{+/+}$ relatives constituted a better-matched control group with shared genetic and environmental features. Moreover, the selection criteria were stricter for UHVs, compared with both family groups, with volunteers excluded on the basis of psychiatric disorders, including substance-use disorders. This noted, since the functional connectivity alterations in the $D C C^{+/-}$carriers differed from one of the two control groups only, these particular results should be interpreted with caution.

\section{Volumetric alterations}

Striatal volumetric reductions were seen in DCC-haploinsufficient humans and mice. These striatal effects occurred ventrally in mice and more dorsally in humans. The different locus of effect might plausibly be explained by anatomical and functional differences between the species. First, in rodents there is a clear dissociation between mesolimbic (VTA to VS) and nigrostriatal (SN to dorsal striatum) pathways (Düzel et al., 2009), whereas in humans, mesolimbic pathways originate from both the VTA and SN (Düzel et al., 2009). Second, the VS comprises the NAcc and olfactory tu- bercle in rodents, whereas in primates it also includes ventral aspects of the putamen and caudate nucleus (Haber et al., 1990; Holt et al., 1997). Finally, the dorsal striatum, comprising the unified caudate-putamen in rodents, exists as two structures in humans (caudate nucleus and putamen) separated by the internal capsule, a bundle of fibers richly expressing DCC (Shu et al., 2000).

The NAcc volumetric reductions identified in adolescent and adult $D c c^{+/-}$mice are interesting in light of the previously reported NAcc findings, including reduced dopamine fiber innervation, blunted amphetamine-induced dopamine release, and disrupted amphetamine-induced behaviors (Hoops and Flores, 2017). Since the striatal volumetric reductions are present in adolescence, they precede the dopamine pathway alterations observed in adult, and not adolescent, $D c^{+/-}$mice (Hoops and Flores, 2017). Since the precise etiology of these volumetric effects is unknown, they may be driven by DCC-induced alterations to either dopaminergic or nondopaminergic neurons. Moreover, developmental changes between adolescence and adulthood were identified: striatal and hippocampal volumes increased while mPFC volumes decreased, and these effects were independent of genotype.

The human putamen effect might not be restricted to rare $D C C$ mutations. Indeed, a recent large genome-wide association study in the general population $(n=30,717)$ found that putamen volume was influenced by four genes, including a single nucleotide polymorphism (SNP) in an intronic locus of DCC (Hibar et al., 2015). To our knowledge, the consequence of this SNP on the expression or function of the DCC protein is unknown. In comparison, in the present a priori hypothesis-guided study, knowing that the mutated allele results in nonfunctional DCC protein (Srour et al., 2010), we have strengthened the evidence for and identified the direction of this DCC-associated effect on human putamen.

\section{Personality traits, substance use, and associations with mesocorticolimbic connectivity}

The low novelty-seeking trait scores and low tobacco-use findings among $D C C^{+/-}$humans are remarkably consistent with the phenotype of adult $D c c^{+/-}$mice, which exhibit blunted stimulant drug-induced behavioral responses and reduced intracranial self-stimulation reward (Grant et al., 2007; Yetnikoff et al., 2007; Flores, 2011; Kim et al., 2013; Reynolds et al., 2016). Noveltyseeking scores in the $D C C^{+/-}$mutation carriers were reduced compared with both control groups, whereas cigarette use was reduced compared with $D C C^{+/+}$relatives only. Although the lack of differences in cigarette use between $D C C^{+/-}$and UHV groups diminishes the robustness of the finding, the result is not unanticipated given that problematic tobacco and other substance use were exclusion criteria for UHVs. Finally, lifetime cannabis use was negatively correlated with anatomical connectivity between the SN/VTA and hippocampus. This finding was not hypothesized a priori, though it might have some bearing with respect to previously reported evidence of anatomical connectivity reductions in hippocampal pathways among long-term cannabis users (Zalesky et al., 2012).

\section{Limitations}

The present study should be considered in light of the following. First, there are general limitations of diffusion MRI tractography to infer fiber pathways, including indirect measurement of axonal orientations and the challenge of resolving crossing fibers (Jones et al., 2013; Jbabdi et al., 2015). However, the tractography maps from the SN/VTA accord closely with tract-tracing studies 
in macaques (Haber, 2014) with main projections to the striatum, prefrontal, and limbic areas. Second, functional and diffusion MRI cannot discern the direction or neurochemistry of axonal projections, but postmortem DCC mapping studies (Harter et al., 2010; Manitt et al., 2013; Reyes et al., 2013) and the growing animal literature (Osborne et al., 2005; Manitt et al., 2010; Flores, 2011; Hoops and Flores, 2017) suggest that dopamine neurons and their postsynaptic targets are likely prominent contributors. Third, our sample size is modest (20 DCC mutation carriers and 36 controls). This noted, the a priori hypotheses were guided by an in-depth animal literature (Flores, 2011; Hoops and Flores, 2017), the haploinsufficient DCC mutation is known to produce nonfunctional DCC protein (Srour et al., 2010), and the sample size is the largest DTI study of DCC mutation carriers reported to date. Previous studies evaluated corticospinal pathways in seven carriers in one study (Marsh et al., 2017) and two carriers in another (Welniarz et al., 2017). A third study evaluated whole-brain connectivity in just one carrier (Jamuar et al., 2017). Thus, though caution is warranted as with any novel observation, we propose that the clear a priori hypotheses, the carefully matched samples, and the general robustness of the core findings provide some confidence.

\section{Conclusions}

We have identified in humans for the first time the effects of a mutated axon guidance receptor gene on mesocorticolimbic connectivity, terminal region volumes, and mesocorticolimbicrelated behaviors. Strikingly, the striatal volume reductions were seen in both DCC-haploinsufficient humans and mice. Together these effects of DCC haploinsufficiency might have implications for understanding recently reported associations between genetic variations in this axon guidance receptor and neuropsychiatric disorders (Grant et al., 2012; Manitt et al., 2013; Dunn et al., 2016; Okbay et al., 2016; Yan et al., 2016; Torres-Berrío et al., 2017; Ward et al., 2017; Zeng et al., 2017; Leday et al., 2018).

\section{References}

Andersson JL, Jenkinson M, Smith S (2007) Non-linear registration, aka Spatial normalization. FMRIB technical report TR07JA2. FMRIB Analysis Group of the University of Oxford 2. Oxford, UK: FMRIB Centre.

Bartra O, McGuire JT, Kable JW (2013) The valuation system: a coordinatebased meta-analysis of BOLD fMRI experiments examining neural correlates of subjective value. Neuroimage 76:412-427. CrossRef Medline

Behrens TE, Berg HJ, Jbabdi S, Rushworth MF, Woolrich MW (2007) Probabilistic diffusion tractography with multiple fibre orientations: what can we gain? Neuroimage 34:144-155. CrossRef Medline

Biswal BB, Mennes M, Zuo XN, Gohel S, Kelly C, Smith SM, Beckmann CF, Adelstein JS, Buckner RL, Colcombe S, Dogonowski AM, Ernst M, Fair D, Hampson M, Hoptman MJ, Hyde JS, Kiviniemi VJ, Kötter R, Li SJ, Lin CP, et al. (2010) Toward discovery science of human brain function. Proc Natl Acad Sci U S A 107:4734-4739. CrossRef Medline

Caseras X, Avila C, Torrubia R (2003) The measurement of individual differences in behavioural inhibition and behavioural activation systems: a comparison of personality scales. Pers Ind Diff 34:999-1013. CrossRef

De Fruyt F, Van De Wiele L, Van Heeringen C (2000) Cloninger's psychobiological model of temperament and character and the five-factor model of personality. Pers Ind Diff 29:441-452. CrossRef

Desikan RS, Ségonne F, Fischl B, Quinn BT, Dickerson BC, Blacker D, Buckner RL, Dale AM, Maguire RP, Hyman BT, Albert MS, Killiany RJ (2006) An automated labeling system for subdividing the human cerebral cortex on MRI scans into gyral based regions of interest. Neuroimage 31:968980. CrossRef Medline

Dunn EC, Wiste A, Radmanesh F, Almli LM, Gogarten SM, Sofer T, Faul JD, Kardia SL, Smith JA, Weir DR, Zhao W, Soare TW, Mirza SS, Hek K, Tiemeier H, Goveas JS, Sarto GE, Snively BM, Cornelis M, Koenen KC, et al. (2016) Genome-wide association study (GWAS) and genome-wide by environment interaction study (GWEIS) of depressive symptoms in
African American and Hispanic/Latina women. Depress Anxiety 33:265280. CrossRef Medline

Düzel E, Bunzeck N, Guitart-Masip M, Wittmann B, Schott BH, Tobler PN (2009) Functional imaging of the human dopaminergic midbrain. Trends Neurosci 32:321-328. CrossRef Medline

Fazeli A, Dickinson SL, Hermiston ML, Tighe RV, Steen RG, Small CG, Stoeckli ET, Keino-Masu K, Masu M, Rayburn H, Simons J, Bronson RT, Gordon JI, Tessier-Lavigne M, Weinberg RA (1997) Phenotype of mice lacking functional deleted in colorectal cancer (Dcc) gene. Nature 386: 796-804. CrossRef Medline

Flores C (2011) Role of netrin-1 in the organization and function of the mesocorticolimbic dopamine system. J Psychiatry Neurosci 36:296-310. CrossRef Medline

Flores C, Manitt C, Rodaros D, Thompson KM, Rajabi H, Luk KC, Tritsch NX, Sadikot AF, Stewart J, Kennedy TE (2005) Netrin receptor deficient mice exhibit functional reorganization of dopaminergic systems and do not sensitize to amphetamine. Mol Psychiatry 10:606-612. CrossRef Medline

Frank MJ, Seeberger LC, O'reilly RC (2004) By carrot or by stick: cognitive reinforcement learning in parkinsonism. Science 306:1940-1943. CrossRef Medline

Fritz CO, Morris PE, Richler JJ (2012) Effect size estimates: current use, calculations, and interpretation. J Exp Psychol Gen 141:2-18. CrossRef Medline

Gad JM, Keeling SL, Wilks AF, Tan SS, Cooper HM (1997) The expression patterns of guidance receptors, DCC and Neogenin, are spatially and temporally distinct throughout mouse embryogenesis. Dev Biol 192:258 273. CrossRef Medline

Grant A, Hoops D, Labelle-Dumais C, Prévost M, Rajabi H, Kolb B, Stewart J, Arvanitogiannis A, Flores C (2007) Netrin-1 receptor-deficient mice show enhanced mesocortical dopamine transmission and blunted behavioural responses to amphetamine. Eur J Neurosci 26:3215-3228. CrossRef Medline

Grant A, Fathalli F, Rouleau G, Joober R, Flores C (2012) Association between schizophrenia and genetic variation in DCC: a case-control study. Schizophr Res 137:26-31. CrossRef Medline

Haber SN (2014) The place of dopamine in the cortico-basal ganglia circuit. Neuroscience 282:248-257. CrossRef Medline

Haber SN, Lynd E, Klein C, Groenewegen HJ (1990) Topographic organization of the ventral striatal efferent projections in the rhesus monkey: an anterograde tracing study. J Comp Neurol 293:282-298. CrossRef Medline

Harter PN, Bunz B, Dietz K, Hoffmann K, Meyermann R, Mittelbronn M (2010) Spatio-temporal deleted in colorectal cancer (DCC) and netrin-1 expression in human foetal brain development. Neuropathol Appl Neurobiol 36:623-635. CrossRef Medline

Hibar DP, Stein JL, Renteria ME, Arias-Vasquez A, Desrivières S, Jahanshad N, Toro R, Wittfeld K, Abramovic L, Andersson M, Aribisala BS, Armstrong NJ, Bernard M, Bohlken MM, Boks MP, Bralten J, Brown AA, Chakravarty MM, Chen Q, Ching CR, et al. (2015) Common genetic variants influence human subcortical brain structures. Nature 520:224-229. CrossRef Medline

Holt DJ, Graybiel AM, Saper CB (1997) Neurochemical architecture of the human striatum. J Comp Neurol 384:1-25. CrossRef Medline

Hoops D, Flores C (2017) Making dopamine connections in adolescence. Trends Neurosci 40:709-719. CrossRef Medline

Jamuar SS, Schmitz-Abe K, D'Gama AM, Drottar M, Chan WM, Peeva M, Servattalab S, Lam AN, Delgado MR, Clegg NJ, Zayed ZA, Dogar MA, Alorainy IA, Jamea AA, Abu-Amero K, Griebel M, Ward W, Lein ES, Markianos K, Barkovich AJ, et al. (2017) Biallelic mutations in human DCC cause developmental split-brain syndrome. Nat Genet 49:606-612. CrossRef Medline

Jbabdi S, Sotiropoulos SN, Haber SN, Van Essen DC, Behrens TE (2015) Measuring macroscopic brain connections in vivo. Nat Neurosci 18: 1546-1555. CrossRef Medline

Jenkinson M, Smith S (2001) A global optimisation method for robust affine registration of brain images. Med Image Anal 5:143-156. CrossRef Medline

Jones DK, Knösche TR, Turner R (2013) White matter integrity, fiber count, and other fallacies: the do's and don'ts of diffusion MRI. Neuroimage 73:239-254. CrossRef Medline

Keuken MC, Forstmann BU (2015) A probabilistic atlas of the basal ganglia using 7 T MRI. Data Brief 4:577-582. CrossRef Medline

Kim JH, Lavan D, Chen N, Flores C, Cooper H, Lawrence AJ (2013) 
Netrin-1 receptor-deficient mice show age-specific impairment in druginduced locomotor hyperactivity but still self-administer methamphetamine. Psychopharmacology 230:607-616. CrossRef Medline

Leday GGR, Vértes PE, Richardson S, Greene JR, Regan T, Khan S, Henderson R, Freeman TC, Pariante CM, Harrison NA, Perry VH, Drevets WC, Wittenberg GM, Bullmore ET (2018) Replicable and coupled changes in innate and adaptive immune gene expression in two case-control studies of blood microarrays in major depressive disorder. Biol Psychiatry 83:7080. CrossRef Medline

Leyton M, Boileau I, Benkelfat C, Diksic M, Baker G, Dagher A (2002) Amphetamine-induced increases in extracellular dopamine, drug wanting, and novelty seeking: a PET/[11C] raclopride study in healthy men. Neuropsychopharmacology 27:1027-1035. CrossRef Medline

Livesey FJ, Hunt SP (1997) Netrin and netrin receptor expression in the embryonic mammalian nervous system suggests roles in retinal, striatal, nigral, and cerebellar development. Mol Cell Neurosci 8:417-429. CrossRef Medline

Manitt C, Labelle-Dumais C, Eng C, Grant A, Mimee A, Stroh T, Flores C (2010) Peri-pubertal emergence of UNC-5 homologue expression by dopamine neurons in rodents. PLoS One 5:e11463. CrossRef Medline

Manitt C, Mimee A, Eng C, Pokinko M, Stroh T, Cooper HM, Kolb B, Flores C (2011) The netrin receptor DCC is required in the pubertal organization of mesocortical dopamine circuitry. J Neurosci 31:8381-8394. CrossRef Medline

Manitt C, Eng C, Pokinko M, Ryan RT, Torres-Berrío A, Lopez JP, Yogendran SV, Daubaras MJ, Grant A, Schmidt ER, Tronche F, Krimpenfort P, Cooper HM, Pasterkamp RJ, Kolb B, Turecki G, Wong TP, Nestler EJ, Giros B, Flores C (2013) DCC orchestrates the development of the prefrontal cortex during adolescence and is altered in psychiatric patients. Transl Psychiatry 3:e338. CrossRef Medline

Marsh AP, Heron D, Edwards TJ, Quartier A, Galea C, Nava C, Rastetter A, Moutard ML, Anderson V, Bitoun P, Bunt J, Faudet A, Garel C, Gillies G, Gobius I, Guegan J, Heide S, Keren B, Lesne F, Lukic V, et al. (2017) Mutations in DCC cause isolated agenesis of the corpus callosum with incomplete penetrance. Nat Genet 49:511-514. CrossRef Medline

Okbay A, Baselmans BM, De Neve JE, Turley P, Nivard MG, Fontana MA, Meddens SF, Linnér RK, Rietveld CA, Derringer J, Gratten J, Lee JJ, Liu JZ, de Vlaming R, Ahluwalia TS, Buchwald J, Cavadino A, Frazier-Wood AC, Furlotte NA, Garfield V (2016) Genetic variants associated with subjective well-being, depressive symptoms, and neuroticism identified through genome-wide analyses. Nat Genet 48:624-633. CrossRef Medline

Osborne P, Halliday GM, Cooper HM, Keast JR (2005) Localization of immunoreactivity for deleted in colorectal cancer (DCC), the receptor for the guidance factor netrin-1, in ventral tier dopamine projection pathways in adult rodents. Neuroscience 131:671-681. CrossRef Medline

Paxinos G, Franklin KB (2004) The mouse brain in stereotaxic coordinates. Houston, Texas: Gulf Professional Publishing.

Pokinko M, Moquin L, Torres-Berrío A, Gratton A, Flores C (2015) Resilience to amphetamine in mouse models of netrin-1 haploinsufficiency: role of mesocortical dopamine. Psychopharmacology 232:3719-3729. CrossRef Medline

Reyes S, Fu Y, Double KL, Cottam V, Thompson LH, Kirik D, Paxinos G, Watson C, Cooper HM, Halliday GM (2013) Trophic factors differentiate dopamine neurons vulnerable to Parkinson's disease. Neurobiol Aging 34:873-886. CrossRef Medline

Reynolds LM, Gifuni AJ, McCrea ET, Shizgal P, Flores C (2016) dcc haploinsufficiency results in blunted sensitivity to cocaine enhancement of reward seeking. Behav Brain Res 298:27-31. CrossRef Medline
Reynolds LM, Pokinko M, Torres-Berrío A, Cuesta S, Lambert LC, Del Cid Pellitero E, Wodzinski M, Manitt C, Krimpenfort P, Kolb B, Flores C (2018) DCC receptors drive prefrontal cortex maturation by determining dopamine axon targeting in adolescence. Biol Psychiatry 83:181-192. CrossRef Medline

Rousseeuw PJ, Hubert M (2011) Robust statistics for outlier detection. WIREs Data Mining Knowl Discov 1:73-79. CrossRef

Shu T, Valentino KM, Seaman C, Cooper HM, Richards LJ (2000) Expression of the netrin-1 receptor, deleted in colorectal cancer (DCC), is largely confined to projecting neurons in the developing forebrain. J Comp Neurol 416:201-212. CrossRef Medline

Smith SM, Nichols TE (2009) Threshold-free cluster enhancement: addressing problems of smoothing, threshold dependence and localisation in cluster inference. Neuroimage 44:83-98. CrossRef Medline

Smith SM, Jenkinson M, Johansen-Berg H, Rueckert D, Nichols TE, Mackay CE, Watkins KE, Ciccarelli O, Cader MZ, Matthews PM, Behrens TE (2006) Tract-based spatial statistics: voxelwise analysis of multi-subject diffusion data. Neuroimage 31:1487-1505. CrossRef Medline

Srour M, Philibert M, Dion MH, Duquette A, Richer F, Rouleau GA, Chouinard S (2009) Familial congenital mirror movements: report of a large 4-generation family. Neurology 73:729-731. CrossRef Medline

Srour M, Rivière JB, Pham JM, Dubé MP, Girard S, Morin S, Dion PA, Asselin G, Rochefort D, Hince P, Diab S, Sharafaddinzadeh N, Chouinard S, Théoret H, Charron F, Rouleau GA (2010) Mutations in DCC cause congenital mirror movements. Science 328:592. CrossRef Medline

Torres-Berrío A, Lopez JP, Bagot RC, Nouel D, Dal Bo G, Cuesta S, Zhu L, Manitt C, Eng C, Cooper HM, Storch KF, Turecki G, Nestler EJ, Flores C (2017) DCC confers susceptibility to depression-like behaviors in humans and mice and is regulated by miR-218. Biol Psychiatry 81:306-315. CrossRef Medline

Ward J, Strawbridge RJ, Bailey MES, Graham N, Ferguson A, Lyall DM, Cullen B, Pidgeon LM, Cavanagh J, Mackay DF, Pell JP, O’Donovan M, Escott-Price V, Smith DJ (2017) Genome-wide analysis in UK biobank identifies four loci associated with mood instability and genetic correlation with major depressive disorder, anxiety disorder and schizophrenia. Trans Psychiatry 7:1264. CrossRef Medline

Welniarz Q, Morel MP, Pourchet O, Gallea C, Lamy JC, Cincotta M, Doulazmi M, Belle M, Méneret A, Trouillard O, Ruiz M, Brochard V, Meunier S, Trembleau A, Vidailhet M, Chédotal A, Dusart I, Roze E (2017) Non cell-autonomous role of DCC in the guidance of the corticospinal tract at the midline. Sci Rep 7:410. CrossRef Medline

Yan P, Qiao X, Wu H, Yin F, Zhang J, Ji Y, Wei S, Lai J (2016) An association study between genetic polymorphisms in functional regions of five genes and the risk of schizophrenia. J Mol Neurosci 59:366-375. CrossRef Medline

Yetnikoff L, Labelle-Dumais C, Flores C (2007) Regulation of netrin-1 receptors by amphetamine in the adult brain. Neuroscience 150:764-773. CrossRef Medline

Zalesky A, Solowij N, Yücel M, Lubman DI, Takagi M, Harding IH, Lorenzetti V, Wang R, Searle K, Pantelis C, Seal M (2012) Effect of long-term cannabis use on axonal fibre connectivity. Brain 135:2245-2255. CrossRef Medline

Zeng Y, Navarro P, Fernandez-Pujals AM, Hall LS, Clarke TK, Thomson PA, Smith BH, Hocking LJ, Padmanabhan S, Hayward C, MacIntyre DJ, Wray NR, Wray NR, Deary IJ, Porteous DJ, Haley CS, McIntosh AM (2017) A combined pathway and regional heritability analysis indicates NETRIN1 pathway is associated with major depressive disorder. Biol Psychiatry 81:336-346. CrossRef Medline 